\title{
APPLICATION OF CHLOROPHYLL FLUORESCENCE TO STUDY IRON AND MANGANESE DEFICIENCIES IN PEACH TREE
}

\section{J. Val, M. Sanz, L. Montañés and E. Monge}

Estación Experimental de Aula Dei, C.S.I.C. PO BOX 202 50080-Zaragoza (Spain).

Key words: chlorophyll fluorescence, Fe deficiency, Mn deficiency, peach tree, photosynthetic pigments, photosystem II, Prunus persica.

\section{Abstract}

The study of the mechanisms that modify the chlorophyll fluorescence emission can be used to characterize the physiological behaviour of plants as affected by mineral deficiencies or excesses. The aim of this paper was to carry out a preliminary study of the application of chlorophyll fluorescence as an alternative for identifying iron and manganese deficiencies in peach tree leaves under field growing conditions. For this purpose in a peach tree orchard leaf samples (control, Fe deficient and Mn deficient) were taken from the basal (old) and apical (young) part of the shoots. The samples were analyzed for $\mathrm{Mn}, \mathrm{Fe}$, and photosynthetic pigments. Modulated fluorescence and kinetics of fluorescence were recorded in the sampled material. Both manganese and iron deficiencies decreased variable chlorophyll fluorescence (Fv). Iron deficient leaves showed low Fv/Fp $(\approx 0.77)$ and Fv/Fm $(\approx 0.70)$ ratios as evidence of diminished PS II photochemistry. However, old manganese deficient leaves provided the same Fv/Fp $(\approx 0.78)$ ratio as controls, while manganese deficiency in young leaves produced high Fo, which indicates a greater extent of antenna versus PS II reaction centers. From these findings a derived consequence has been obtained: it may be possible to detect subclinical manganese deficiencies in the field, that is to say, before visual symptoms have developed.

Abbreviations: Chl, chlorophyll; F, Fluorescence (subscripts $0, \mathrm{p}$ or $\mathrm{m}$ and $\mathrm{v}$ define minimal, maximal and variable levels); - Fe, iron-deficient; - Mn, manganese-deficient; PS, Photosystem.

\section{Introduction}

Some nutritional deficiencies are characterized by specific visual symptoms. Chlorosis and/or necrosis in leaves are useful symptoms to diagnose mineral nutrient disorders in plants. In field conditions, both iron and manganese deficiencies promote interveinal chlorosis, but while iron deficiency always begins in the youngest leaves and all veins are green, in the case of 
manganese chlorosis usually starts in the oldest leaves and only the main ribs remain green.

Chlorophyll fluorescence is a powerful tool to study some plant nutritional deficiencies (Kriedemann et al., 1985, 1988, Val and Monge, 1990, Val et al., 1992). For each quantum of energy captured by the chlorophyll in the red region of the spectrum, the promotion of an electron is induced from its fundamental state to an excited state. Absorption in the blue causes an even greater excitation as a quantum in this region is more energetic. A large fraction goes to drive carbon assimilation, while a minute fraction of this excitation energy is re-emitted as light (mostly as chlorophyll fluorescence). Although this is trivial in quantity it has proved invaluable as an indicator of photochemical events and its measurement has recently opened up entirely new possibilities (Schreiber, 1983, Val and Baker, 1989, Walker, 1992).

Chlorophyll fluorescence, determined in leaf, has been used to investigate the status of $\mathrm{Mn}$ in plants. The $\mathrm{Fv} / \mathrm{Fp}$ ratio ( $\mathrm{Fv}=\mathrm{Fp}-\mathrm{Fo}$ ) provides a good indication of the physiological state of the plant under stress of Mn (Kriedemann et al., 1988). In a fluorescence study with intact leaves of $\mathrm{Mn}$ deficient wheat plants, Kriedemann et al. (1985) found that in comparison with controls, the deficiency results in: a strong increase in Fo, a FV decrease, together with a clear loss of capacity to evolve $\mathrm{O}_{2}$, and a reduction of the chlorophyll $a / b$ ratio. These authors assign the changes observed in the fluorescence parameters and in the photosynthetic electron transport to a substantial loss of PS II reaction centers, as was already observed through electron microscopy (Simpson and Robinson, 1984).

A number of studies of fluorescence emission in Fe-deficient leaves have been carried out (Morales et al., 1992, Val et al., 1992). These have shown that severe iron deficiency produces an irreversible decrease in the PS II photochemistry.

The purpose of this study was to investigate the application of chlorophyll fluorescence as an alternative for identifying iron and manganese deficiencies in peach tree leaves under field growing conditions. This has been endorsed by the analysis of mineral elements, and photosynthetic pigments.

\section{Materials and Methods}

\subsection{Plant material}

Old and young leaves were taken from an 11-year-old peach tree orchard (Prunus persica L. Batsch cv. Baby Gold 7) located in El Temple (Huesca, Spain). The samples were taken during the second half of July. All control, iron and manganese deficient leaves were first visually recognized. In spite of the fact that young manganese deficient leaves do not show visual symptoms, these could be sampled by taking leaves from the apical part of the shoots showing Mn deficiency symptoms in their oldest leaves. 


\subsection{Mn and Fe analysis.}

After washing with a detergent solution (phosphate free), tap and deionized water, the leaves were dried in a forced draft furnace $\left(65 \pm 5^{\circ} \mathrm{C}\right)$, and finally ground for mineral analysis. These were analyzed by using the methods proposed by the Inter-Institutes Committee (1969), and Pinta and C.I.I. (1973), The results were expressed as $\mathrm{mg} \mathrm{kg}^{-1}$ of $\mathrm{dry}$ matter.

\subsection{HPLC Analysis of Photosynthetic Pigments.}

Photosynthetic pigments were extracted from 10 leaf discs of known area $\left(0.358 \mathrm{~cm}^{2}\right.$ each) by grinding in a mortar with $10 \mathrm{~mL}$ of cold $100 \%$ acetone, and $40-50 \mathrm{mg}$ of sodium ascorbate. Extraction procedures were carried out in dimmed room light. Extracts were stored at $-30^{\circ} \mathrm{C}$ until use. Pigment analyses were carried out by $\mathrm{rp}^{-\mathrm{C}_{18}} \mathrm{HPLC}$ (Val and Monge, 1990).

\subsection{Modulated Fluorescence and Fluorescence Kinetics in Leaves}

For fluorescence experiments, the leaves were excised from the trees, and immediately kept within several layers of water moistened paper. Fluorescence determinations were preceded by a $60-\mathrm{min}$. period of dark adaptation and were carried out on the upper leaf surface.

Modulated chlorophyll-a fluorescence was measured using a Hansatech pulse amplitude modulation fluorometer. Fluorescence was excited with a measuring beam of weak light from a pulsed light-emitting diode and a $620 \mathrm{~nm}$ cut off filter to obtain Fo (all reaction centres open). Detection was measured at $700 \mathrm{~nm}$. Maximum fluorescence yield, Fp was determined by application of white light $\left(800 \mu \mathrm{mol} \mathrm{m} \mathrm{m}^{-2}\right)$ to close the reaction centres. The variable fluorescence, Fv, was calculated by the difference between $\mathrm{Fp}$ and Fo.

The kinetics of induction of chlorophyll fluorescence in excised leaves was measured basically as described previously (Val and Baker, 1989). Briefly, the leaf was introduced in a clip which holds one fibreoptics which drives light (PPFD of $1500 \mu \mathrm{mol} \mathrm{m} \mathrm{m}^{-2} \mathrm{~s}^{-1}$ ) from an halogen source stabilized and a cut off filter of $620 \mathrm{~nm}$ (> $620 \mathrm{~nm}, 35-5404$, Ealing, Watford, UK); and at 90 degrees the detector is located (FDP/ 2-92106, Hansatech, Norkfold, U.K.) that solely collects the fluorescence emission at $680 \mathrm{~nm}$ through an interference filter (35-4068, Ealing, Watford, UK).

The signals of modulated fluorescence were recorded during $20 \mathrm{sec}-$ onds at a frequency of $10 \mathrm{~Hz}$ by a 12 bit resolution ADD card (PCL-711S, Advantech) and a Labtech Acquire software (Lab. Tech. Corp.) installed in a 386Personal Computer. The analogical signal derived from the kinetics of fluorescence in leaves was also withdrawal in the computer plus a software Unkelscope Jr. (Unkel Software, Massachusetts, USA) during 1 second at a frequency of $4 \mathrm{kHz}$. The ASCll files that contain both kind of curves (200 
points for modulated and 4000 for the kinetics of fluorescence) were processed and monitored through Microsoft Excel 4.0.

\section{Results and Discussion}

Manganese deficiency could be easily identified by mineral plant analysis. However, leaves suffering from lime induced chlorosis often have a content of total iron similar or even higher than that of green leaves (Heras et al., 1976). In table 1 iron and manganese leaf concentrations of the investigated samples are shown. All the other elements could be considered as current values for these kind of samples (data not shown). The manganese concentrations of the -Mn samples (old and young) are clearly below $20 \mathrm{mg} \mathrm{kg}^{-1}$, which is the reported value for deficiency in the literature for Prunus persica leaves sampled at approximately the same time and taken from the middle of the shoot (Bergmann, 1992, Jones et al., 1991, Reuter and Robinson, 1986). Old manganese deficient leaves contain less chlorophyll per area unit than those of control. In contrast to that, no significant differences either in pigment concentrations or in their ratios were found between young manganese deficient and young control leaves (table 2). Therefore, manganese deficiency in young leaves cannot be detected by means of visual diagnosis or by studying the pigment composition.

As expected, total leaf iron concentration in young leaves (table 1) did not provide coherent information with the visually detected iron deficiency, which was corroborated by the very low leaf chlorophyll concentration in these samples (table 2). Iron deficiency is currently identified by eye and also by photosynthetic pigments analysis, which usually results in higher chlorophyll $a / b$ and lower chlorophyll/carotenoids ratios than control plants (Monge et al., 1987, Val et al., 1987) as shown in table 2.

Chlorophyll fluorescence is today a well established test for photochemical activity of the PS II. Fluorescence studies in leaves from plants which are iron or manganese stressed were carried out (Kriedemann et al., 1985; Morales et al, 1991, Val et al., 1992), but until now, few experiments relating fluorescence to mineral deficiencies in field conditions have been made.

Modulated fluorescence measurements (the same applies for fast kinetics) in both old and young iron deficient peach tree leaves (table 3) show that these kind of leaves, compared with those of control, have a diminished photosynthetic PS II capability (lower Fv/Fp than controls). These results were validated during the time spent to carry out the measurements and also during the days in which the repetitions were made. Negligible time-dependent differences were found, that is to say, the behaviour of all the six kind of samples (old and young leaves of control, $-\mathrm{Fe}$ and $-\mathrm{Mn}$ ) was always consistent in terms of fluorescence parameters during the time of the experiment (data not shown).

Interestingly, in the case of old iron deficient leaves Fo and $\mathrm{Fp}$ values are much higher than the corresponding values of controls. This is consistent with the data obtained in Anacystis nidulans by Guikema (1985), who attributed 
these aberrant fluorescence characteristics to dramatic changes in the thylakoid membrane organization. Similar results were obtained when the kinetics of fluorescence with continuous actinic light was recorded (table 3).

Manganese deficient young leaves without visible symptoms of chlorosis produced the characteristic curves already reported for manganese deficient soybeans in climatic chamber ( $\mathrm{Val}$ et al., 1992). High values of Fo corresponding with low Fv are indicative of a greater extent of the light harvesting structures compared to PS II core complexes. The curious topic in this case is that old manganese deficient leaves respond in a very similar way to controls (table 3), even though the symptoms of chlorosis are clearly visible. This indicates that the green zones of $-\mathrm{Mn}$ leaves behave and, in fact, are very similar to control leaf tissues, and the fluorescence contribution of their yellow zones is masked by the green ones. Young -Mn leaves, without apparent loss of chlorophyll, show an homogeneous pigmentation and the lack of manganese only produces alterations in the stoichiometry between core and antenna complexes providing the characteristic fluorescence parameters for Mn deficient material (table 3).

The practical interest of these experiments, which deserves further investigation, lies in the possibility of early detection (before the symptoms have developed) and subsequent correction of some nutritional disorders as was demonstrated for manganese deficiency. This may be possible for instance by means of simple portable fluorometers, which are now freely available.

Unfortunately, until now there is no way by fluorescence techniques to diagnose the iron deficiency before the symptoms developed. As reported by Pérez et al. (1994) when iron-deficiency occurs, the chloroplasts suffer an adaptation in order to safeguard their maximum photosynthetic capacity. When the iron-deficiency is not severe the stoichiometry among different pigments-protein complexes remains unchanged, as well as the ratio between the photosynthetic pigments of these complexes. Therefore, the changes in fluorescence parameters could only be detected to late to be of use to perform an early diagnosis

\section{Acknowledgements}

The authors thank to: C. Fustero, M.A. Gracia, C. Lope and J. Pascual for their technical contribution. This paper was supported by projects PCA 4/91 and 6/91 (Research Advisory Board. Diputación General de Aragón) and AGR90-0792 (National Plan for Agricultural Research).

\section{References}

Bergmann, W. 1992. Nutritional Disorders of Plants. Visual and Analytical Diagnosis. Gustav Fisher. Jena. Germany

Comité Inter-Institutos (C.I.I.) 1969. Métodos de referencia para la determinación de elementos minerales en vegetales. An. Edaf. Agrobiol. XXVIII: 403-417. 
Guikema, J.A. 1985. Fluorescence induction characteristics of Anacystis nidulans during recovery from iron deficiency. J. Plant Nutr. 8: 891-908.

Heras, L., Sanz, M., y Montañés, L., 1976. Corrección de la clorosis férrica en melocotonero y su repercusión sobre el contenido mineral, relaciones nutritivas y rendimientos. An. Aula Dei 13 (Zaragoza): 261-287.

Jones, Jr. J., Wolf, B., and Mills, H.A. 1991. Plant Analysis Handbook. Micro-Macro Publishing, Athens, USA.

Kriedemann, P. E., Graham, R.D., and Wiskich, J.T. 1985. Photosynthetic dysfunction and in vivo changes in chlorophyll a fluorescence from manganese-deficient wheat leaves. Aust. J. Agric. Res. 36: 157-169

Kriedemann, P.E., and Anderson, J.E. 1988. Growth and photosynthetic responses to manganese and copper deficiencies in wheat (Triticum aestivum) and barley grass (Hordeum glaucum ). Aust. J. Plant Physiol. 15: $429-446$

Monge, E., Val, J., Heras, L., and Abadia, J. 1987. Photosynthetic pigment composition of higher plants grown under iron stress. Progr. Photosyn. Res. 4: 201-208.

Morales, F., Abadia, A., and Abadia, J. 1991. Chlorophyll fluorescence and photon yield of oxygen evolution in iron-deficient (Beta vulgaris, L.) leaves. Plant Physiol. 97, 886-893

Morales, F., Susín, S., Abadía, A., and Abadía, J. 1992. Photosynthetic characteristics or iron chlorotic pear (Pyrus communis, L.). J. Plant Nutr. 15: 1783-1790.

Pérez, C., Val, J., and Monge, E. 1994. Effects of iron deficiency on photosynthetic structures in peach (Prunus Persica [L.] Batsch) leaves. In: Iron in soils and plants. J. Abadía, ed. Kluwer Academic Publishers. In press.

Pinta, M. et C.I.I. 1973. Méthodes de référence pour la détermination des éléments mineraux dans les végétaux. Détérmination des élements $\mathrm{Ca}, \mathrm{Mg}$, $\mathrm{Fe}, \mathrm{Mn}, \mathrm{Zn}$, et $\mathrm{Cu}$ par absorption atomique. Oléagineux, 28: 87-93.

Reuter, D.J., and Robinson, J.B. 1986. Plant Analysis. An interpretative manual. Inkata Press. Melbourne. Australia.

Schreiber, U. 1983. Technical review. Chlorophyll fluorescence yield changes as a tool in plant physiology. I. The measuring system. Photosyn. Res. 4: 361-373.

Simpson, D. J., and Robinson, S.P. 1984. Freeze-fracture ultrastructure of the thylakoid membranes in chloroplasts from manganese deficient plants. Plant Physiol. 74: 735-741

Val, J., Heras, L., Abadia, J., and Monge, E. 1987. Changes in photosynthetic pigment composition in higher plants as affected by iron nutrition status. J. Plant Nutr. 10: 995-1001.

Val; J., and Baker, N. 1989. Light-dependent, chilling effects on phosphorylation of thylakoid proteins and consequences for associated photochemical activities in maize. Physiol. Plant. 77: 420-426

Val. J., and Monge, E. 1990. Violaxanthin cycle and fluorescence in irondeficient maize leaves. Current Research in Photosynthesis, 4: 765-768. 
Val, J., Pérez, M.C., Madero, M.P., Pequerul, A., and Monge. E. 1992. Are manganese and iron deficiencies so similar.? ...Fluorescence, a way of study. In: Optimization of Plant Nutrition. M.A.C. Fragoso and M.L. Beusichen. Eds. pp 491-496. Kluwer Acad. Publ. Netherlands.

Walker, D. 1992. Excited leaves. New Phytologists. 121: 325-345 
Table 1. Leaf iron and manganese concentrations $\left(\mathrm{mg} \mathrm{kg}^{-1}\right)$ of control, manganese and iron deficient old and young leaves from peach tree $(C,-$ $M n$ and $-F e$ respectively). Values are the mean $\pm S D(n=10)$.

\begin{tabular}{|c|c|c|c|c|c|c|}
\hline & \multicolumn{2}{|l|}{ c } & \multicolumn{2}{|l|}{$-M n$} & \multicolumn{2}{|l|}{$-\mathrm{Fe}$} \\
\hline & Old & Young & Old & Young & Old & Young \\
\hline Iron & $156.7 \pm 9.53$ & $89.35 \pm 8.52$ & $126.1 \pm 13.5$ & $93.5 \pm 6.1$ & $85.1 \pm 5.2$ & $90.4 \pm 5.6$ \\
\hline Manganese & $31.4 \pm 1.5$ & $20.75 \pm 2.3$ & $15.4 \pm 0.9$ & $15.8 \pm 0.1$ & $22.2 \pm 1.5$ & $24.2 \pm 2.3$ \\
\hline
\end{tabular}

Table 2. Photosynthetic pigment leaf concentrations $\left(\mu \mathrm{g} \mathrm{cm}^{-2}\right)$ and ratios of control, manganese and iron deficient old and young leaves from peach tree (C, $-\mathrm{Mn}$ and $-\mathrm{Fe}$ respectively). Values are the mean $\pm S D$ $(n=10)$.

\begin{tabular}{|c|c|c|c|c|c|c|}
\hline & \multicolumn{2}{|l|}{ c } & \multicolumn{2}{|l|}{$-M n$} & \multicolumn{2}{|l|}{$-\mathrm{Fe}$} \\
\hline & Old & Young & Old & Young & Old & Young \\
\hline Total Chl & $44.62 \pm 3.33$ & $34.30 \pm 5.23$ & $23.23 \pm 5.63$ & $31.31 \pm 1.23$ & $9.34 \pm 1.23$ & $11.83 \pm 2.11$ \\
\hline $\mathrm{Chl}$ a/b ratio & $3.04 \pm 0.56$ & $3.16 \pm 0.36$ & $2.95 \pm 0.36$ & $3.20 \pm 0.08$ & $3.42 \pm 0.21$ & $4.05 \pm 0.07$ \\
\hline Carotenoids & $12.97 \pm 0.95$ & $12.97 \pm 2.35$ & $9.22 \pm 1.24$ & $11.98 \pm 0.99$ & $3.15 \pm 0.08$ & $6.16 \pm 0.85$ \\
\hline Chl/Carotenoids & $3.46 \pm 0.45$ & $2.68 \pm 0.28$ & $2.52 \pm 0.17$ & $2.61 \pm 0.15$ & $2.97 \pm 0.09$ & $1.92 \pm 0.12$ \\
\hline
\end{tabular}


Table 3. Some relevant modulated and fast kinetics fluorescence parameters (relative units) obtained from control, manganese and iron deficient old and young peach tree leaves ( $C,-\mathrm{Mn}$ and $-\mathrm{Fe}$ respectively). Values are the mean $\pm \operatorname{SD}(n=10)$.

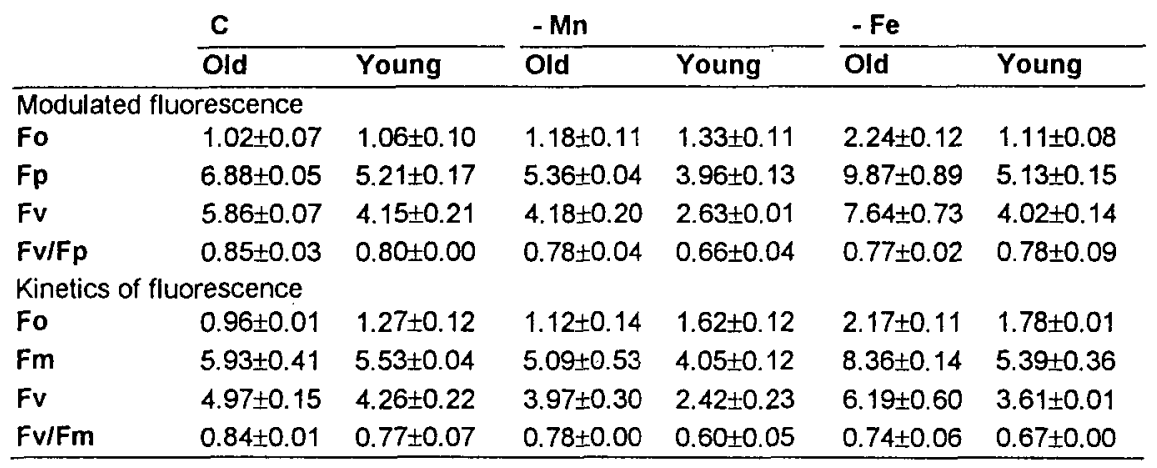

